\title{
The effect of heat treatment on the morphology and mobility of Au nanoparticles
}

\author{
Sven Oras ${ }^{1,2,3}$, Sergei Vlassov ${ }^{*}$, Simon Vigonski ${ }^{4}$, Boris Polyakov ${ }^{5}$, Mikk Antsov ${ }^{1}$, \\ Vahur Zadin ${ }^{4}$, Rünno Lõhmus ${ }^{1}$ and Karine Mougin ${ }^{2}$
}

\author{
Full Research Paper \\ Address: \\ ${ }^{1}$ Institute of Physics, University of Tartu, W. Ostwaldi tn 1, 50412, \\ Tartu, Estonia, ${ }^{2}$ Université de Strasbourg, Université de Haute \\ Alsace, Institut de Science des Matériaux, IS2M-CNRS-UMR 7361, \\ 15 Rue Jean Starcky, 68057 Mulhouse, France, ${ }^{3}$ Tallinn University of \\ Technology, Tartu College, Puiestee 78, Tartu, 51008, Estonia, \\ ${ }^{4}$ Institute of Technology, University of Tartu, Nooruse 1, 50411, Tartu, \\ Estonia and ${ }^{5}$ Institute of Solid State Physics, University of Latvia, \\ Kengaraga street 8, LV-1063 Riga, Latvia \\ Email: \\ Sergei Vlassov* - sergei.vlassov@ut.ee \\ * Corresponding author \\ Keywords: \\ annealing; atomic force microscopy (AFM); Au nanoparticles; \\ manipulation; melting; nanotribology \\ Beilstein J. Nanotechnol. 2020, 11, 61-67. \\ doi:10.3762/bjnano.11.6 \\ Received: 11 July 2019 \\ Accepted: 26 November 2019 \\ Published: 06 January 2020 \\ Associate Editor: T. Glatzel \\ (C) 2020 Oras et al.; licensee Beilstein-Institut. \\ License and terms: see end of document.
}

Open Access

\begin{abstract}
In the present paper, we investigate the effect of heat treatment on the geometry and mobility of Au nanoparticles (NPs) on a Si substrate. Chemically synthesized Au NPs of diameter ranging from 5 to $27 \mathrm{~nm}$ were annealed at 200, 400, 600 and $800{ }^{\circ} \mathrm{C}$ for $1 \mathrm{~h}$. A change in the geometry from faceted to more rounded shapes were observed with increasing annealing temperature. Kinetic Monte Carlo simulations indicate that the NPs become rounded due to the minimization of the surface area and the transition to lower energy surface types $\{111\}$ and $\{100\}$. The NPs were manipulated on a silica substrate with an atomic force microscope (AFM) in tapping mode. Initially, the NPs were immovable by AFM energy dissipation. However, annealed NPs became movable, and less energy was required to displace the NPs annealed at higher temperature. However, after annealing at $800{ }^{\circ} \mathrm{C}$, the particles became immovable again. This effect was attributed to the diffusion of $\mathrm{Au}$ into the $\mathrm{Si}$ substrate and to the growth of the $\mathrm{SiO}_{2}$ layer.
\end{abstract}

\section{Introduction}

Gold is one of the most prominent materials used in studies related to nanostructures. The small size and the enhanced properties of Au nanoparticles (NPs) compared to bulk gold make them important for the development of novel applications, for example, in the field of drug delivery [1], sensor technology [2], printing [3] and catalysis [4]. Due to their inert state, geometrical diversity and convenient synthesis, Au NPs are an attractive model system for nanotribological manipulation experiments [5-12] and simulations [13]. Additional flexibility is provided by the ability to tune the properties of the NPs by varying 
the size [14], shape [14] and chemical composition of the outer layer covering the NP [5]. These modifications become especially important for tribological applications since they can affect the interfacial behavior during contact.

The shape of a NP is known to have a significant impact on the contact area between the NP and a substrate [14]. The morphology, and thus the contact area of the NP, can be tuned by changing the synthesis parameters [15]. For readily synthesized NPs, the morphology can be changed by adding energy to the NPs by laser treatment [16] or by heating the NPs in an oven. Partial melting can be achieved at a significantly lower temperature than the melting temperature of bulk $\mathrm{Au}$ [17].

In this study, chemically synthesized faceted Au NPs were annealed at different temperatures between 200 and $800{ }^{\circ} \mathrm{C}$, which resulted in rounding of the NPs. The particles were then displaced with an atomic force microscope (AFM) in order to study the effect of annealing on their tribological behavior.

\section{Experimental}

\section{Nanoparticle synthesis}

A colloidal suspension of Au NPs was produced by reducing an aqueous solution of $\mathrm{HAuCl}_{4} \cdot \mathrm{H}_{2} \mathrm{O}$. The procedure consisted of adding $3 \mathrm{~mL}$ of $1 \%$ aqueous $\mathrm{HAuCl}_{4}$ (Sigma-Aldrich) to $150 \mathrm{~mL}$ of pure $\mathrm{H}_{2} \mathrm{O}$ at $90{ }^{\circ} \mathrm{C}$ under vigorous stirring. After $1 \mathrm{~min}, 2 \mathrm{~mL}$ of a $1 \%$ aqueous solution of sodium citrate $\left(\mathrm{C}_{6} \mathrm{H}_{5} \mathrm{Na}_{3} \mathrm{O}_{7}\right.$, Sigma-Aldrich) were added to stabilize the suspension. By reducing $\mathrm{HAuCl}_{4}$, sodium citrate transfers the negative charge of the citrate ions to the Au NP surface $[18,19]$. The solution was stirred for $5 \mathrm{~min}$ and then stored at $4{ }^{\circ} \mathrm{C}$ until needed [10].

\section{Annealing}

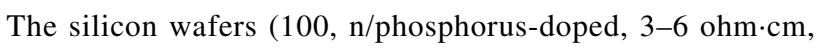
Mat-Technology) were cleaned with ethanol and the NPs were deposited by drop-casting. The drops were dried at ambient conditions. Five samples of Au NPs on Si wafers were prepared, and four of them were then separately annealed in an oven for $1 \mathrm{~h}$ at $200,400,600$ and $800{ }^{\circ} \mathrm{C}$ while the fifth was left untreated. Separate samples were prepared on heat-resistant silicon nitride support films of $50 \mathrm{~nm}$ membrane thickness (Pelco, Ted Pella) to be used for transmission electron microscopy (TEM).

\section{Characterization}

The morphology of the NPs annealed at different temperatures was studied by TEM (ARM200, JEOL). A null ellipsometer (Multiskop, Optrel, Germany) equipped with a $532 \mathrm{~nm}$ $\mathrm{Nd}$ :YAG laser was used for measuring the thickness of the $\mathrm{SiO}_{2}$ layers.

\section{AFM setup}

The manipulation of the NPs was performed with a Bruker Multimode 8 AFM in the PeakForce quantitative nanoscale mechanical characteriztion (PeakForce QNM) mode using a rectangular AFM cantilever (Bruker, RTESPA-300, $k=$ $40 \mathrm{~N} / \mathrm{m}$ ) with a resonance frequency of around $300 \mathrm{kHz}$.

Prior to each manipulation, the samples were heated to $100{ }^{\circ} \mathrm{C}$ to remove excess water. An image was first taken in the highresolution QNM mode to find the Au particles. Then, the operation mode was switched to tapping mode. The oscillation amplitude was kept constant with a feedback loop on, and the power dissipated during tapping was calculated with the following equation [20]:

$$
P=k f_{0}\left(A_{\text {set }} A_{\text {piezo }} \sin \theta-\frac{A_{\text {set }}^{2}}{Q}\right),
$$

where $k$ is the cantilever spring constant, $f_{0}$ is the resonance frequency of the cantilever, $A_{\text {set }}$ is the setpoint amplitude, $A_{\text {piezo }}$ is the drive amplitude, $\theta$ is the phase signal and $Q$ is the quality factor of the AFM cantilever. The dissipated power was used as a measure of the mobility of the NPs.

The calibration of the cantilevers was performed by the thermal tuning method. The oscillation amplitudes ranged from 0.05 to $0.6 \mathrm{~V}$ with a sensitivity of 25 to $31 \mathrm{~nm} / \mathrm{V}$. The sensitivity was measured individually for each cantilever by means of damping the AFM tip against a silicon substrate. The phase values were extracted from the tapping mode phase images for each manipulated NP and processed using the Gwyddion software. The phase shift values were extracted from the profile of the trace on the phase shift image by averaging ten lines using the Gwyddion program.

After each scan, the force applied on the NPs was increased until all the particles in the area were displaced or the force was high enough to start severely damaging the tip. If the tip was too dull for performing manipulations, the tip was replaced with a fresh and sharp AFM tip.

\section{Simulation setup}

Simulations of the NP rounding were carried out using the kinetic Monte Carlo (KMC) code Kimocs [21], which is specifically designed for metal surfaces. The parameters for Au, developed by Vigonski et al. [17], use the tethering method for stabilization [22].

Initially cubic NPs of two sizes with side lengths of 2 and $5 \mathrm{~nm}$ were chosen. The simulations were performed at $726.85{ }^{\circ} \mathrm{C}$ $(1000 \mathrm{~K})$ in order to obtain results within a reasonable computa- 
tion time. This simplification is expected to have only minor influence, especially in the case of a NP diameter of $5 \mathrm{~nm}$ and larger [17]. The parametrization of $\mathrm{Au}$ implemented by Vigonski et al. [17] utilizes only nearest-neighbor jumps, which lead to a rather uniform behavior of larger NPs. In the diffusion model used in Kimocs, the computational time increases exponentially with decreasing temperature, making simulations at experimental temperatures unfeasible. Nevertheless, the temperature used in the simulations is significantly below the melting temperature of $\mathrm{Au}$. Furthermore, in the computational model, the dynamics of diffusion are unaffected by temperature, making comparisons to experimental results possible [21]. Visualizations of the results of the simulation were generated with Ovito [23].

\section{Results and Discussion}

As observed in the TEM images, most of the untreated Au NPs had irregular faceted shapes with a diameter ranging from 5 to $27 \mathrm{~nm}$ with a median diameter of $13 \pm 3.96 \mathrm{~nm}$ (measured on 90 particles). The term "diameter" in the present study was defined as the average value of the largest and the smallest dimension of the NPs visible on the TEM image. A typical TEM image of the synthesized Au NPs is presented in Figure 1.

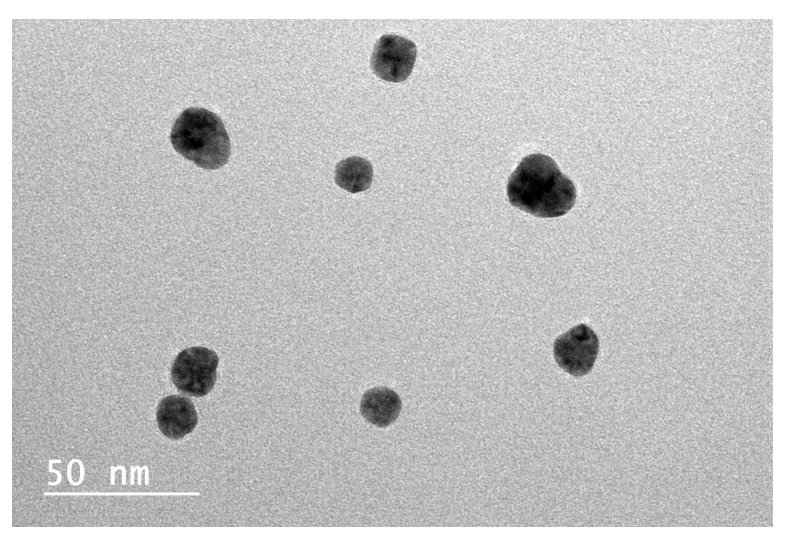

Figure 1: Typical TEM image of Au NPs before thermal treatment.

\section{Influence of temperature - change in morphology}

The TEM analysis revealed a considerable change in the geometry of the NPs to a more rounded shape as a result of annealing, although the temperatures used were far below the melting point of bulk Au $\left(1064{ }^{\circ} \mathrm{C}\right)$. Figure 2 presents typical TEM images of the NPs annealed at different temperatures. Some tendency for rounding can be observed even for the sam-

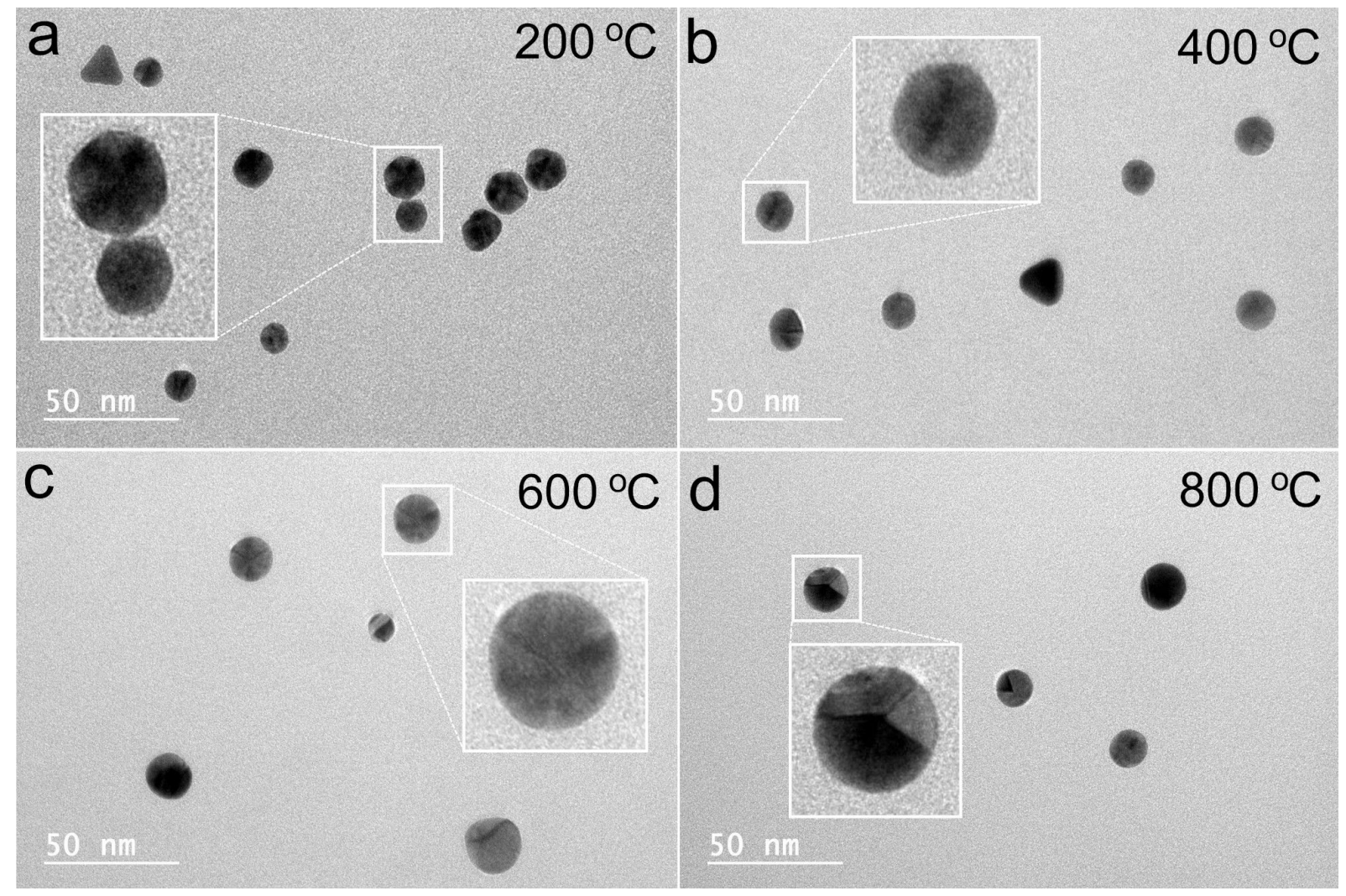

Figure 2: Morphology of the Au NPs and after annealing at (a) 200 (b), 400 (c) 600 (d) and $800{ }^{\circ} \mathrm{C}$. Slight rounding of the NPs can be seen at higher temperatures. 
ple annealed at $200{ }^{\circ} \mathrm{C}$. The effect becomes clearly visible at $400{ }^{\circ} \mathrm{C}$ and increases further for higher temperatures (Table 1). To evaluate the morphological changes more quantitatively, we introduced a criterion based on the length of the facet: if the NP is smaller than $10 \%$ of its total visible perimeter, then it is classified as rounded.

\begin{tabular}{|c|c|c|c|}
\hline Temperature $\left({ }^{\circ} \mathrm{C}\right)$ & Truncated & Rounded & Ratio \\
\hline 200 & 105 & 10 & 10.5 \\
\hline 400 & 64 & 43 & 1.5 \\
\hline 600 & 37 & 42 & 0.9 \\
\hline 800 & 9 & 57 & 0.2 \\
\hline
\end{tabular}

The reduced melting temperature of NPs compared to their bulk counterparts is not a new phenomenon. In 1976, Buffat and Borel [24] demonstrated that the melting temperature of $\mathrm{Au}$ NPs is size-dependent. However, the decrease of the melting temperature presented in their work was only up to a few hundred Kelvin for particles of diameter around $5 \mathrm{~nm}$ and was even less pronounced for larger particles, approaching the melting point of the bulk above $20 \mathrm{~nm}$. In contrast, we observed rounding at much lower temperatures, even for particles exceeding $20 \mathrm{~nm}$ in size. Moreover, rounding of Au NPs at just $500{ }^{\circ} \mathrm{C}$ has been reported even for particles exceeding $100 \mathrm{~nm}$ in diameter [6]. To explain the rounding, it is probably more appropriate to consider the diffusion of surface atoms rather than complete melting. Another important factor for heat-induced morphological changes, overlooked by many other studies, is annealing time. We believe that the surface effects resulting in the rounding of the NPs are due to energy minimization via a rearrangement of surface atoms, similar to the effect demonstrated recently by Vigonski et al. [17] for heat-induced segmentation of Au nanowires at temperatures much below the melting point of bulk Au. We observed that the effect of rounding was more pronounced for NPs with a five-fold twinned inner structure compared to single-crystalline particles in the form of truncated triangles. This can be explained by the presence of inner stresses stored inside the five-fold twinned NPs and the tendency of such particles to seek mechanisms of stress relaxation [25]. The rearrangement of surface atoms into more rounded outer geometries can be a way of energy minimization while preserving the five-fold twinned inner structure of the NP, as shown in Figure 3 for a Au NP heated to $800{ }^{\circ} \mathrm{C}$.

KMC simulations at $726.85{ }^{\circ} \mathrm{C}(1000 \mathrm{~K})$ show that the NPs become rounded through a diffusion process which combines the minimization of the surface area and the transition to lower energy surface types (Figure 4). The preferred surface of face-

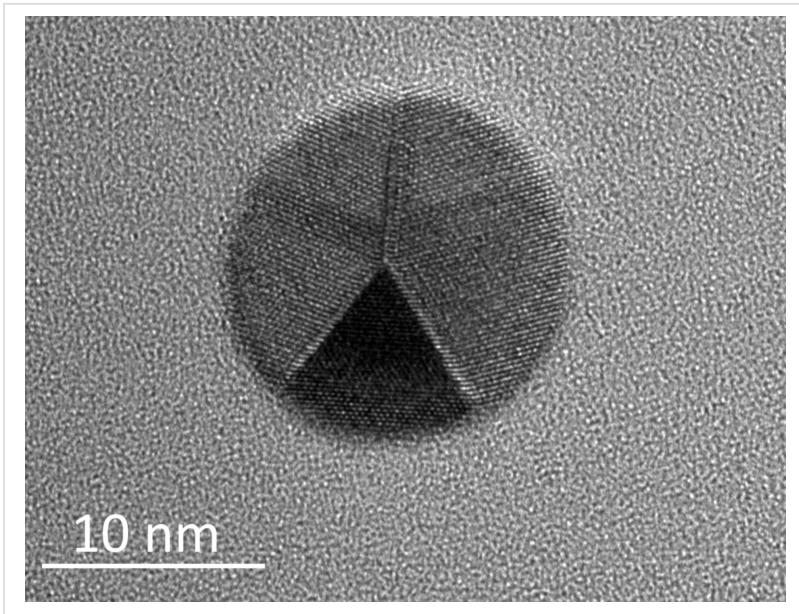

Figure 3: Au NP annealed at $800{ }^{\circ} \mathrm{C}$ with well-pronounced five-fold twinned inner structure.

centered cubic (FCC) materials such as Au is $\{111\}$, and the simulations clearly show that surfaces of this type grow as the NP relaxes. The KMC model used here describes perfect crystals. Therefore, the resulting shape resembles a dodecahedron bounded by the energetically favorable surfaces $\{111\}$ and $\{100\}$. Our simulations do not include five-fold twinned particles and lower temperatures due to limited computational power and time. Advanced modelling and in-depth theoretical analysis of the rounding process lies outside the scope of the present study and should be addressed separately. Nevertheless, this relatively simple model agrees well with the results of our experiments and sheds light on the processes taking place in small metal particles at elevated temperatures.

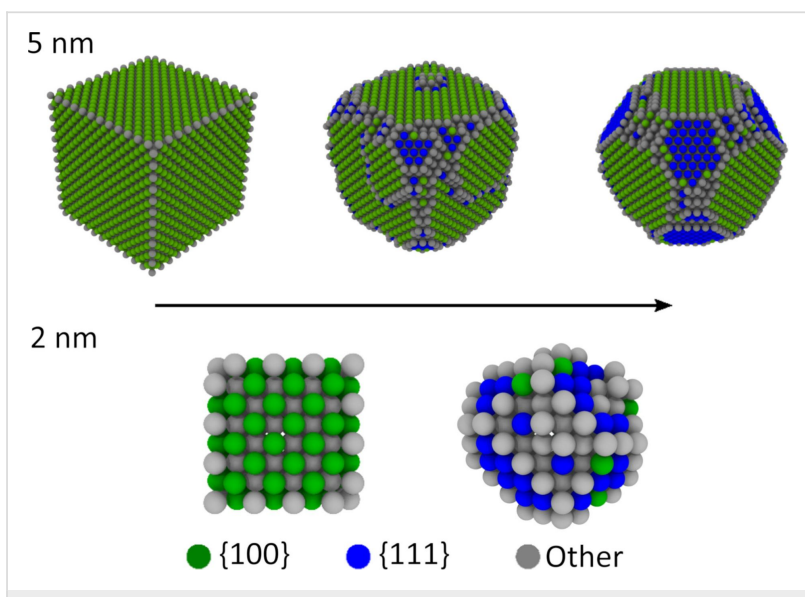

Figure 4: The transition of 5 and $2 \mathrm{~nm}$ NPs into rounded shapes bounded by energetically favorable surfaces. Atoms are colored according to their crystallographic surface type.

\section{Manipulation of Au nanoparticles}

The main goal of this paper was to investigate the effect of the heat-induced rounding of Au NPs on their mobility. Rounding 
of NPs should decrease the contact area compared to faceted particles, and hence reduce the friction forces in accordance with the known relation $\tau=F / A$ [6], where $\tau$ is the contact strength, $F$ is the friction force and $A$ is the contact area. For a round particle, the contact area is determined by contact mechanics $[14,26]$. The contact area of a perfect sphere can be two orders of magnitude smaller than that of a polyhedron-like $\mathrm{NP}$, as was shown by Vlassov and co-workers [6].

The mobility of the Au NPs was evaluated by means of the power dissipated in tapping-mode AFM, which has previously been shown to be an effective technique for the evaluation of NP mobility [10]. An example of the manipulation sequences for the sample annealed at $400{ }^{\circ} \mathrm{C}$ is given in Figure 5. A selected area is scanned in tapping mode, and the driving amplitude is increased until the displacement of NPs is observed. The dissipated power is then calculated.

In total, 34 data points were collected: 12 measurements for NPs annealed at $600{ }^{\circ} \mathrm{C}, 16$ for NPs annealed at $400{ }^{\circ} \mathrm{C}$ and four for NPs annealed at $200{ }^{\circ} \mathrm{C}$ (Figure 6). The low amount of data points for the NPs annealed at $200{ }^{\circ} \mathrm{C}$ is due to the fact that most of the NPs required more power for a displacement than the experimental setup could provide. Therefore, the actual average friction determined for the NPs annealed at $200{ }^{\circ} \mathrm{C}$ is even higher. The power required to displace NPs is the highest for particles annealed at $200{ }^{\circ} \mathrm{C}$ and the lowest for NPs annealed at $600{ }^{\circ} \mathrm{C}$. This finding agrees well with the rounding observed by TEM. Moreover, the amount of dissipated power divided by the radius of the NP (power per NP radius) decreases with increasing size of the NP annealed at $600{ }^{\circ} \mathrm{C}$ series, which may be attributed to a rolling motion as was demonstrated by

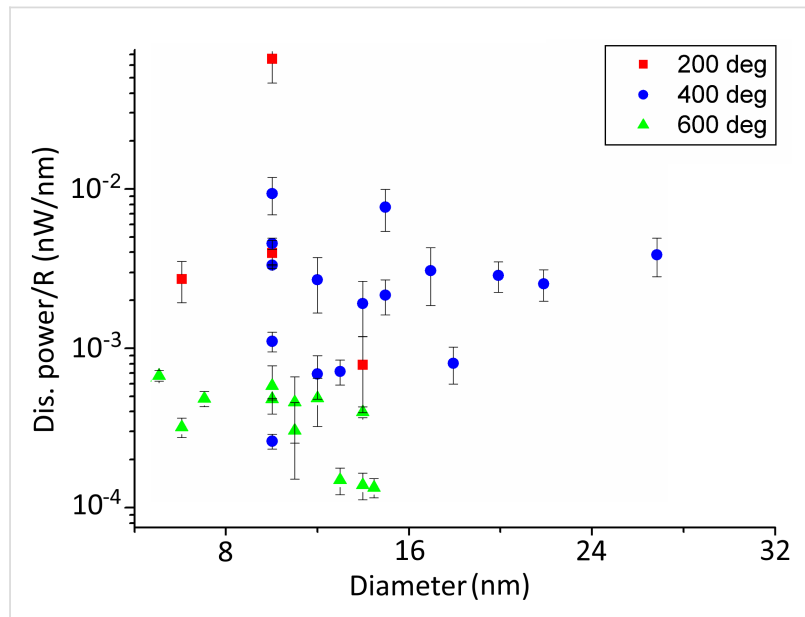

Figure 6: Dissipated power per NP radius as a function of the NP diameter. The diameter is defined as the height of the NP in the AFM image.
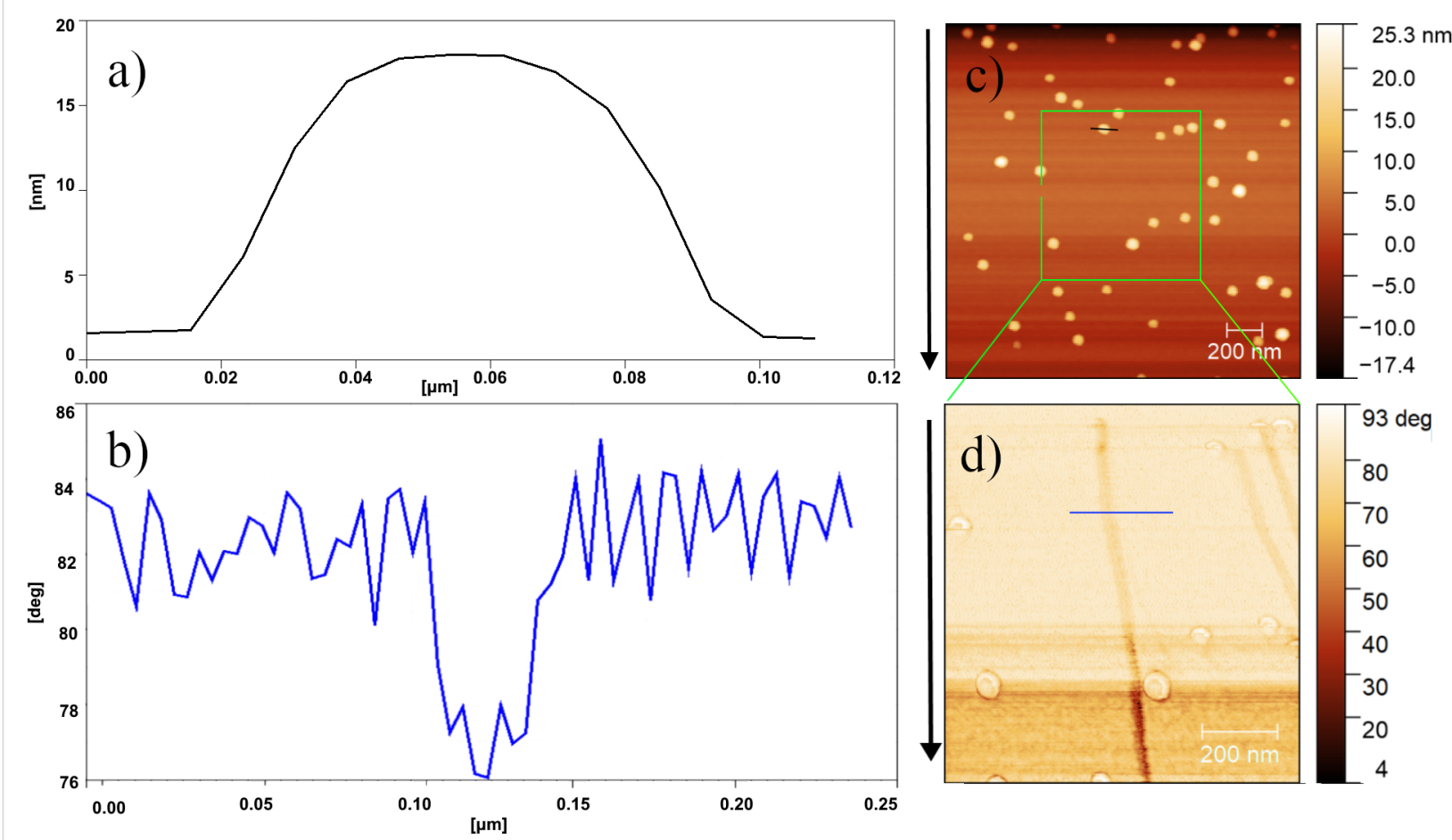

Figure 5: (a) Profile of a Au NP and (b) topography image of NPs on the Si substrate prior to manipulation. (c and d) Phase images recorded during the manipulation. 
Darwich and co-workers [8]. They studied the rolling and sliding motion of NPs as a function of NP size and showed that the dissipated power necessary for sliding has little or no dependence on the NP radius, while the dissipated power needed to provoke rolling decreased clearly with increasing NP radius. The indirect indication of a rolling motion in the present study may serve as additional confirmation of the rounded geometry of the NPs annealed at higher temperatures.

A displacement of both the unannealed NPs and those annealed at $800{ }^{\circ} \mathrm{C}$ was not possible. The immobility of unannealed NPs can be linked to their more pronounced facets (and hence higher surface area) as well as the presence of surfactants that can act as a glue. The immobility of the NPs heated to $800{ }^{\circ} \mathrm{C}$ was surprising, especially considering the fact that they look the most round in the TEM images. One possible explanation is related to the partial diffusion of Au into the Si substrate. It is known that gold diffuses into silicon at higher temperatures by the so-called kick-out mechanism, in which self-interstitials present at thermal equilibrium displace substitutionally dissolved $\mathrm{Au}$ atoms into interstices, such that these may undergo rapid interstitial diffusion [27]. The process is highly temperature-dependent, and diffusion at $800{ }^{\circ} \mathrm{C}$ is four orders of magnitude faster than at $400{ }^{\circ} \mathrm{C}$ (see Table 7 in Fisher [28]). Another reason may be the temperature-sensitive growth of the $\mathrm{SiO}_{2}$ layer [29], which escalates rapidly above $600{ }^{\circ} \mathrm{C}$, as can be seen from the ellipsometry measurements presented in Figure 7. How exactly the rapid growth of the $\mathrm{SiO}_{2}$ layer may be related to the drastic increase in friction remains unclear and can be the subject for future studies. Overall, we demonstrated that heat treatment, which is widely used as a surfactant removal step prior to nanomanipulation experiments, can have extensive effects on the mobility of Au NPs.

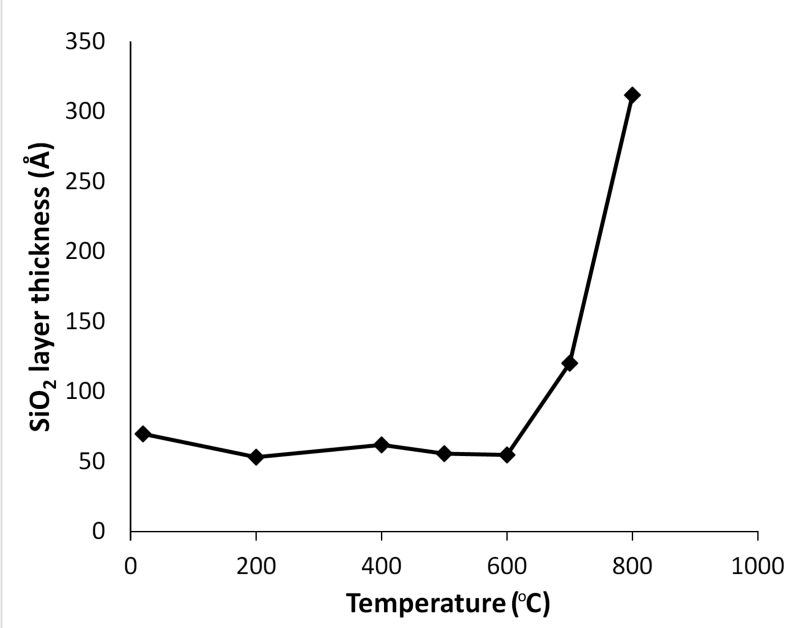

Figure 7: Evolution of the $\mathrm{SiO}_{2}$ layer thickness as a function of the annealing temperature.

\section{Conclusion}

Chemically synthesized Au NPs with a medium diameter of $14 \mathrm{~nm}$ were annealed at 200, 400, 600 and $800{ }^{\circ} \mathrm{C}$ for $1 \mathrm{~h}$. Untreated particles had irregular faceted shapes. Annealing resulted in geometry changes to a more rounded shape. A slight tendency towards rounding was noticed at $200{ }^{\circ} \mathrm{C}$. The rounding effect became clearly prominent at $400{ }^{\circ} \mathrm{C}$ and increased further for higher temperatures. After annealing at $800{ }^{\circ} \mathrm{C}$, most of the particles had sphere-like shapes. KMC simulations at $726.85{ }^{\circ} \mathrm{C}(1000 \mathrm{~K})$ show that the NPs become rounded by a diffusion process that minimizes the surface energy. The process combines minimizing the surface area and transitioning to the lower energy surface types $\{111\}$ and $\{100\}$. In AFM manipulation experiments, it was found that the higher the annealing temperature, the lower the power necessary to displace the NPs, indicating that the mobility of the particles increases at elevated annealing temperature. However, after treatment at $800{ }^{\circ} \mathrm{C}$, the particles became immovable. We attributed this surprising effect to the diffusion of $\mathrm{Au}$ into $\mathrm{Si}$ and to the growth of the $\mathrm{SiO}_{2}$ layer. Both processes are highly temperature-dependent, exhibiting drastic enhancement above $700{ }^{\circ} \mathrm{C}$. Overall, we demonstrated that heat treatment, which is widely used for surfactant removal prior to nanomanipulation experiments, can have an extensive effect on the mobility of $\mathrm{Au}$ NPs.

\section{Funding}

This work was supported by The Centre National de la Recherche Scientifique (CNRS) of France and the French Embassy Program. The authors are also grateful for partial support by COST Action CA15216, the Estonian Science Foundation (grants PUT1689 and PUT1372), the Estonian Centre of Excellence in Zero Energy and Resource Efficient Smart Buildings and Districts, ZEBE, grant 2014-2020.4.01.15.0016 and Latvian Science Council grant lzp- 2018/2-0083.

\section{ORCID ${ }^{\circledR}$ iDs}

Sven Oras - https://orcid.org/0000-0002-8313-8608 Sergei Vlassov - https://orcid.org/0000-0001-9396-4252 Mikk Antsov - https://orcid.org/0000-0003-1291-3520

\section{Preprint}

A non-peer-reviewed version of this article has been previously published as a preprint doi:10.3762/bxiv.2019.68.v1

\section{References}

1. Liu, Y.; Sun, X.; Wang, S.; Xie, M.; Chen, A.; Long, R. Mater. Lett. 2012, 75, 48-50. doi:10.1016/j.matlet.2012.01.137

2. El-Ansary, A. Nanotechnol., Sci. Appl. 2010, 65. doi:10.2147/nsa.s8199 
3. Huang, D.; Liao, F.; Molesa, S.; Redinger, D.; Subramanian, V. J. Electrochem. Soc. 2003, 150, G412. doi:10.1149/1.1582466

4. Thompson, D. T. Nano Today 2007, 2, 40-43. doi:10.1016/s1748-0132(07)70116-0

5. Oras, S.; Vlassov, S.; Berholts, M.; Lõhmus, R.; Mougin, K. Beilstein J. Nanotechnol. 2018, 9, 660-670. doi:10.3762/bjnano.9.61

6. Vlassov, S.; Polyakov, B.; Dorogin, L. M.; Lõhmus, A.; Romanov, A. E.; Kink, I.; Gnecco, E.; Lõhmus, R. Solid State Commun. 2011, 151, 688-692. doi:10.1016/j.ssc.2011.02.020

7. Dietzel, D.; de Wijn, A. S.; Vorholzer, M.; Schirmeisen, A. Nanotechnology 2018, 29, 155702. doi:10.1088/1361-6528/aaac21

8. Darwich, S.; Mougin, K.; Rao, A.; Gnecco, E.; Jayaraman, S.; Haidara, H. Beilstein J. Nanotechnol. 2011, 2, 85-98. doi:10.3762/bjnano.2.10

9. Tong, L.; Zhu, T.; Liu, Z. Appl. Phys. Lett. 2008, 92, 023109. doi:10.1063/1.2822418

10. Mougin, K.; Gnecco, E.; Rao, A.; Cuberes, M. T.; Jayaraman, S.; McFarland, E. W.; Haidara, H.; Meyer, E. Langmuir 2008, 24, 1577-1581. doi:10.1021/la702921v

11. Rao, A.; Wille, M.-L.; Gnecco, E.; Mougin, K.; Meyer, E. Phys. Rev. B 2009, 80, 193405. doi:10.1103/physrevb.80.193405

12. Resch, R.; Lewis, D.; Meltzer, S.; Montoya, N.; Koel, B. E.; Madhukar, A.; Requicha, A. A. G.; Will, P. Ultramicroscopy 2000, 82, 135-139. doi:10.1016/s0304-3991(99)00152-7

13. Guerra, R.; Tosatti, E.; Vanossi, A. Nanoscale 2016, 8, 11108-11113. doi:10.1039/c6nr00520a

14. Polyakov, B.; Vlassov, S.; Dorogin, L. M.; Butikova, J.; Antsov, M.; Oras, S.; Lõhmus, R.; Kink, I. Beilstein J. Nanotechnol. 2014, 5 , 133-140. doi:10.3762/bjnano.5.13

15. Grzelczak, M.; Pérez-Juste, J.; Mulvaney, P.; Liz-Marzán, L. M. Chem. Soc. Rev. 2008, 37, 1783. doi:10.1039/b711490g

16. Polyakov, B.; Vlassov, S.; Dorogin, L. M.; Novoselska, N.; Butikova, J.; Antsov, M.; Oras, S.; Lohmus, R.; Kink, I. Nanoscale Res. Lett. 2014, 9, 186. doi:10.1186/1556-276x-9-186

17. Vigonski, S.; Jansson, V.; Vlassov, S.; Polyakov, B.; Baibuz, E.; Oras, S.; Aabloo, A.; Djurabekova, F.; Zadin, V. Nanotechnology 2018, 29, 015704. doi:10.1088/1361-6528/aa9a1b

18. Frens, G. Nature (London), Phys. Sci. 1973, 241, 20-22. doi:10.1038/physci241020a0

19. Grabar, K. C.; Allison, K. J.; Baker, B. E.; Bright, R. M.; Brown, K. R.; Freeman, R. G.; Fox, A. P.; Keating, C. D.; Musick, M. D.; Natan, M. J. Langmuir 1996, 12, 2353-2361. doi:10.1021/la950561h

20. Anczykowski, B.; Gotsmann, B.; Fuchs, H.; Cleveland, J. P.; Elings, V. B. Appl. Surf. Sci. 1999, 140, 376-382. doi:10.1016/s0169-4332(98)00558-3

21. Jansson, V.; Baibuz, E.; Djurabekova, F. Nanotechnology 2016, 27, 265708. doi:10.1088/0957-4484/27/26/265708

22. Baibuz, E.; Vigonski, S.; Lahtinen, J.; Zhao, J.; Jansson, V.; Zadin, V.; Djurabekova, F. Comput. Mater. Sci. 2018, 146, 287-302. doi:10.1016/j.commatsci.2017.12.054

23. Stukowski, A. Modell. Simul. Mater. Sci. Eng. 2010, 18, 015012. doi:10.1088/0965-0393/18/1/015012

24. Buffat, P.; Borel, J.-P. Phys. Rev. A 1976, 13, 2287-2298. doi:10.1103/physreva.13.2287

25. Dorogin, L. M.; Vlassov, S.; Kolesnikova, A. L.; Kink, I.; Lõhmus, R.; Romanov, A. E. Phys. Status Solidi B 2010, 247, 288-298. doi:10.1002/pssb.200945385

26. Derjaguin, B. V.; Muller, V. M.; Toporov, Yu. P. J. Colloid Interface Sci. 1975, 53, 314-326. doi:10.1016/0021-9797(75)90018-1
27. Seeger, A. Phys. Status Solidi A 1980, 61, 521-529. doi:10.1002/pssa.2210610225

28. Fisher, D. J. Diffusion in Silicon - 10 Years of Research; Scitec Publications: Zuerich-Uetikon, Switzerland, 1998; p 248.

29. Gorantla, S.; Muthuvenkatraman, S.; Venkat, R. IEEE Trans. Electron Devices 1998, 45, 336-338. doi:10.1109/16.658853

\section{License and Terms}

This is an Open Access article under the terms of the Creative Commons Attribution License (https://creativecommons.org/licenses/by/4.0). Please note that the reuse, redistribution and reproduction in particular requires that the authors and source are credited.

The license is subject to the Beilstein Journal of Nanotechnology terms and conditions:

(https://www.beilstein-journals.org/bjnano)

The definitive version of this article is the electronic one which can be found at: doi:10.3762/bjnano.11.6 